\title{
DÜBLIN
}

Technological University Dublin

ARROW@TU Dublin

\section{Rapid analysis of magnesium in infant formula powder using laser-induced breakdown spectroscopy}

\author{
Maria Markiewicz-Keszycka \\ Technological University Dublin, Maria.MarkiewiczKeszycka@TUDublin.ie \\ Ming Zhao \\ University College Dublin, Ireland \\ Xavier Cama-Moncunill \\ Technological University Dublin
}

See next page for additional authors

Follow this and additional works at: https://arrow.tudublin.ie/schfsehart

Part of the Analytical Chemistry Commons, and the Food Chemistry Commons

\section{Recommended Citation \\ Maria Markiewicz-Keszycka, Ming Zhao, Xavier Cama-Moncunill, Toufic El Arnaout, Dana Becker, Colm O'Donnell, Patrick J. Cullen, Carl Sullivan, Maria P. Casado-Gavalda, Rapid analysis of magnesium in infant formula powder using laser-induced breakdown spectroscopy, International Dairy Journal, Volume 97, 2019, Pages 57-64, ISSN 0958-6946, DOI: 10.1016/j.idairyj.2019.05.010.}

This Article is brought to you for free and open access by the School of Food Science and Environmental Health at ARROW@TU Dublin. It has been accepted for inclusion in Articles by an authorized administrator of ARROW@TU Dublin. For more information, please contact arrow.admin@tudublin.ie, aisling.coyne@tudublin.ie, gerard.connolly@tudublin.ie.

Funder: Department of Agriculture, Food and the Marine, Ireland

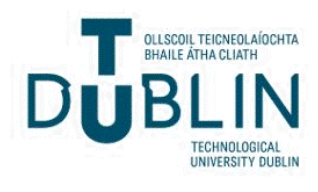




\section{Authors}

Maria Markiewicz-Keszycka, Ming Zhao, Xavier Cama-Moncunill, Toufic El Arnaout, Dana Becker, Colm O'Donnell, P. J. Cullen, Carl Sullivan, and Maria Piedad Casado-Gavalda 


\title{
Rapid analysis of magnesium in infant formula powder using laser-induced breakdown spectroscopy
}

\author{
Maria Markiewicz-Keszycka ${ }^{\text {a, }}{ }^{*}$, Ming Zhao ${ }^{b}$, Xavier Cama-Moncunill a, \\ Toufic El Arnaout a, Dana Becker ${ }^{c}$, Colm O'Donnell ${ }^{\text {b }}$, Patrick J. Cullen ${ }^{\text {a, d }}$, Carl Sullivan ${ }^{\text {a }}$, \\ Maria P. Casado-Gavalda ${ }^{\text {a }}$ \\ a School of Food Science and Environmental Health, Dublin Institute of Technology, Cathal Brugha St., Dublin 1, Ireland \\ ${ }^{\mathrm{b}}$ UCD School of Biosystems and Food Engineering, University College Dublin, Belfield, Dublin 4, Ireland \\ c Department of Food Technology, Trier University of Applied Sciences, Trier, Germany \\ d School of Chemical and Biomolecular Engineering, University of Sydney, Sydney, Australia
}

\section{A R T I C L E I N F O}

\section{Article history:}

Received 20 March 2019

Received in revised form

20 May 2019

Accepted 20 May 2019

Available online 4 June 2019

\begin{abstract}
A B S T R A C T
Laser-induced breakdown spectroscopy (LIBS) was investigated to determine magnesium (Mg) content in infant formula powder. To predict $\mathrm{Mg}$ content in the range established by the Codex Alimentarius, a partial least squares regression (PLSR) model was developed using a calibration data set $(\mathrm{n}=30$ ) based on full cross-validation and validated using an independent validation data set $(n=21)$. The prediction model performance was evaluated using the regression coefficients of determination $\left(R_{\mathrm{cv}}^{2}=0.94\right.$ and $\mathrm{R}_{\mathrm{p}}^{2}=0.85$ ) with the root mean square errors on cross-validation and prediction (RMSECV $=60 \mathrm{mg} \mathrm{kg} \mathrm{g}^{-1}$ and $\left.\operatorname{RMSEP}=80 \mathrm{mg} \mathrm{kg}^{-1}\right)$. The limit of detection $\left(150 \mathrm{mg} \mathrm{kg}^{-1}\right)$ was also calculated. In addition, LIBS successfully predicted the Mg content distributed within a pellet. This study demonstrated that LIBS is suitable as a rapid reagent-free method for the quantification of $\mathrm{Mg}$ in powdered infant formula and can provide spatial information with acceptable accuracy.
\end{abstract}

๑) 2019 Elsevier Ltd. All rights reserved.

\section{Introduction}

Adequate nutrition during infancy is of paramount importance for child development; early nutritional deficiencies can affect long-term growth and health. Although WHO considers breast milk as the ideal nutrition for infants, the number of children fed with infant formula at some point of their life is increasing. Infant formula is intended to supplement or substitute human milk and is mostly produced in a powder format using a spray drying process (Hanley et al., 2011). To ensure high quality infant formulas, the Codex Alimentarius provides standards and guidelines to protect consumers' health and to ensure fair trade practices globally. Furthermore, according to the EU Regulation 2016/127 of 25 September 2015, the information contained on infant formula and follow-on formula label should provide the amount of twelve minerals among other compounds listed in Annex I to this Regulation.

\footnotetext{
* Corresponding author. Tel.: +35314024520

E-mail address: Maria.MarkiewiczKeszycka@dit.ie (M. Markiewicz-Keszycka).
}

Magnesium, an essential mineral for life, has multiple physiological functions and is the second most abundant intracellular cation and the fourth most abundant cation in a human body. Approximately $60 \%$ of the total body magnesium is located in the bone while the remainder is in the soft tissues (JahnenDechent \& Ketteler, 2012). It plays a crucial role in many physiological functions by impacting the synthesis of biomacromolecules such as DNA, RNA and proteins. Almost all enzymatic processes using phosphorus as an energy source require magnesium for activation. This element is also crucial for regulating muscle contraction, nerve impulse conduction, vascular tone, and normal heart function by regulating the active transport of calcium and potassium ions across cell membranes (Rigo et al., 2017).

Current analytical methods used to determine $\mathrm{Mg}$ and other minerals in milk and dairy products, such as atomic absorption spectroscopy (AAS) or inductively coupled plasma optical emission spectrometry/mass spectrometry (ICP-OES/MS) are time-consuming and require lengthy sample preparation steps and toxic chemicals. These techniques are very effective, but not suitable for fast screening analysis in the factory environment. 
Thus, there is a need in the industry for the development and validation of rapid reagent-free methods for the mineral determination in dairy ingredients and infant formula.

The LIBS technique is based on a simple plasma spectrochemical approach. A high powered Q-switched (pulse mode) Nd:YAG (neodymium-doped: yttrium aluminium garnet) laser is focused on a sample to produce a plasma plume whose emission contains characteristic spectral signatures from excited atoms, radicals, and ions. Emission from different atomic species usually occur at different times after laser ignition, thus to obtain a spectral fingerprint of the atomic species that are present in the sample time-resolved detection is needed. The Q-switched mode allows laser pulses (also referred to as pulse width) of 5-1000 ns in duration. The emitted radiation is collected by optical fibres and transferred to a spectrometer that is an essential part of the LIBS system and comprises a spectrograph and a detector. The spectrograph splits the incoming light into a frequency spectrum and the detector measures the intensity of the different frequencies of the electromagnetic radiation (Markiewicz-Keszycka et al., 2017). The light intensity as a function of wavelength is recorded in a computer as a spectrum that can provide identification as well as concentration information about the various elements present in the sample (Rai, Yueh, Singh, \& Rai, 2007). The spectrum within the range from 190 to $850 \mathrm{~nm}$ is typically analysed with LIBS. Some elements with non-metallic character have their strongest lines below 190, as such they are challenging to detect due to atmospheric absorption and special efforts are required to minimise attenuation due to ambient air in the VUV region (Thakur \& Singh, 2007).

LIBS as an entirely optical technique is considered a suitable process analytical technology (PAT) tool for qualitative and quantitative chemical analysis. PAT was originally introduced for the pharmaceutical industry to design, analyse and control manufacturing actions through the measurement of critical process parameters (CPPs) related to critical quality attributes (CQAs) of raw and in-processed materials (Wang et al., 2018). Thus, the impact of novel PAT instruments on product quality and safety, process efficiency and yields could be notable.

Chemometric modelling is of paramount importance to fully interpret and utilise the true potential of spectral data. LIBS spectra are usually very rich and provide a large number of variables in the wavelength range of $180-900 \mathrm{~nm}$. Partial least squares regression (PLSR) modelling aims to investigate collinearity of spectral data and chemical references by compressing and projecting data matrices towards their common directions called as loading vectors or latent variables (LVs).

LIBS combined with chemometrics has been previously employed to determine minerals, contaminants and other food components in milk, bakery products, tea, fruits, vegetables, water, cereals and meat (Bilge et al., 2016; Casado-Gavalda et al., 2017; Kim, Kwak, Choi, \& Park, 2012; Multari, Cremers, Dupre, \& Gustafson, 2013). However, there is a relatively small number of published studies on the potential of LIBS for determination and quantification of magnesium in food and dairy products (Alfarraj, Sanghapi, Bhatt, Yueh, \& Singh, 2018; Kim et al., 2012; Lei et al., 2011; Silvestre, Barbosa, Aguiar, Leme, \& Nomura, 2015).

This study evaluates LIBS coupled with chemometrics for the determinations of magnesium in infant formula powders, therefore it makes an original contribution to this field. PLSR modelling based on LIBS spectra and the chemical reference of $\mathrm{Mg}$ were used to develop models for the prediction of $\mathrm{Mg}$ content in infant formula as well as spatially within the area of a sample.

\section{Material and methods}

\subsection{Sample preparation}

Infant formula powder was purchased from the Irish market. Two calibration batches and one validation batch, containing samples with varying concentration of $\mathrm{Mg}$, were prepared independently, on different days. For clarification purposes, these batches will further be referred as batch $1 \mathrm{c}$, batch $2 \mathrm{c}$ and batch $3 \mathrm{v}$. Batches $1 \mathrm{c}$ and $2 \mathrm{c}$ contained five samples with varying content of magnesium and batch $3 \mathrm{v}$ contained two extra samples not included in the calibration batches. All samples were prepared in three replicates to give an experimental design of 3 replicates $\times 10$ samples (batch $1 \mathrm{c}$ and $2 \mathrm{c}$ ) +3 replicates $\times 7$ samples (batch $3 \mathrm{v}$ ) $(\mathrm{n}=51)$.

To avoid problems with mixing of very small amounts of $\mathrm{MgCl}_{2}$ (Sigma Aldrich, Arklow, Ireland) with IF, a premix with high Mg concentration was firstly prepared by mixing $5 \mathrm{~g} \mathrm{MgCl}_{2}$ with $95 \mathrm{~g}$ IF. Consequently, the magnesium concentration in the first premix was $13,000 \mathrm{mg} \mathrm{kg}^{-1}$. This premix was the starting point to produce its subsequent dilutions with pure infant formula. Detailed formulation of subsequent premixes used to obtain calibration and validation samples can be found in Table 1.

To ensure precise mixing of infant formula with $\mathrm{MgCl}_{2}$ premixes or lactose, the blending process was divided into two parts. Firstly, mixtures were ground in a laboratory blender equipped with rotatory stainless-steel blades (8011G, Waring Laboratory Science, CT, USA) for 2 min, which resulted in the reduction and homogenisation of particle size. Subsequently, the ground mixtures were transferred to a laboratory V-mixer (FTLMV-1L, Filtra Vibracion S.L., Spain) and dry mixing was applied for $20 \mathrm{~min}$. Preparation of pellets was performed according to (Cama-Mocunill et al., 2018) with slight modifications. Every experimental sample was carefully weighed $(400 \pm 20 \mathrm{mg})$ and transferred into a $13 \mathrm{~mm}$ diameter

Table 1

Formulation of infant formula-Mg and infant formula-lactose mixtures.

\begin{tabular}{|c|c|c|c|c|c|}
\hline Sample name & IF weight (g) & Added premix name & Added premix weight (g) & Total weight $(\mathrm{g})$ & Estimated $\mathrm{Mg}$ content $\left(\mathrm{mg} \mathrm{kg}^{-1}\right)$ \\
\hline Pre-Mg 1 & 95.00 & $\mathrm{MgCl}_{2}$ & 5.00 & 100 & 13,088 \\
\hline Pre-Mg 2 & 70.00 & Pre-Mg 1 & 30.00 & 100 & 4164 \\
\hline Pre-Mg 3 & 70.00 & Pre-Mg 2 & 30.00 & 100 & 1487 \\
\hline $\operatorname{Mg} 4$ & 65.00 & Pre-Mg 3 & 35.00 & 100 & 742 \\
\hline Mg V2 & 45.00 & $\operatorname{Mg} 4$ & 60.00 & 105 & 569 \\
\hline Pre-Mg 4 & 70.00 & Pre-Mg 3 & 15.00 & 85 & 542 \\
\hline $\operatorname{Mg} 3$ & 50.00 & Pre-Mg 4 & 50.00 & 100 & 441 \\
\hline Pre-Mg 5 & 35.00 & Lactose & 65.00 & 100 & 119 \\
\hline Mg V1 & 40.00 & $\operatorname{Mg} 2$ & 70.00 & 110 & 298 \\
\hline $\operatorname{Mg} 2$ & 40.00 & $\operatorname{Mg} 1$ & 60.00 & 100 & 274 \\
\hline Mg 1 & 50.00 & Pre-Mg 5 & 50.00 & 100 & 230 \\
\hline
\end{tabular}


stainless steel die. Samples without any binder were then pelleted using a hydraulic press (GS01160, Specac Ltd., Orpington, UK) by applying a pressure of 10 tonnes for $1 \mathrm{~min}$.

\subsection{Reference analysis}

Atomic absorption spectroscopy (AAS) (Varian 55B AA, Agilent Technologies, USA) was used as a reference method to determine magnesium content in the calibration and validation samples. First, all samples were mineralised with 69\% nitric acid (CAS 7697-37-2, Sigma Aldrich). Acid digestion was conducted in triplicates in MarsXpress ${ }^{\circledR}$ Vessels in a Microwave Accelerated Reaction System (CEM Corp. MARS 6, Matthews, NC, USA), following the CEM procedure for infant formula. Briefly, $500 \mathrm{mg}$ of the sample was weighed into the digestion vessel and then $10 \mathrm{~mL} 69 \% \mathrm{HNO}_{3}$ was added. The mixtures were carefully swirled and left in open vessels for $15 \mathrm{~min}$ for pre-digestion. The microwave heating program consisted of ramping from ambient temperature to $200{ }^{\circ} \mathrm{C}$ in $20 \mathrm{~min}$ and holding this temperature for $15 \mathrm{~min}$. After cooling, the digested solutions were transferred to $50 \mathrm{~mL}$ volumetric flasks, and the volume was made up with high-purity deionised water. Further dilutions with deionised water were carried out to maintain $\mathrm{Mg}$ concentrations within the AAS optimum measuring range (0-1 ppm). AAS parameters are described elsewhere (MarkiewiczKeszycka et al., 2018).

\subsection{LIBS instrumentation}

LIBS analysis was performed with a LIBSCAN-150 system (Applied Photonics Limited, Skipton, North Yorkshire, UK). The system used a Q-switched Nd:YAG laser operating at its fundamental wavelength $(\lambda=1064 \mathrm{~nm})$ (ultra Quantel laser, Bozeman, MT, USA), generating $5 \mathrm{~ns}$ duration pulses at an energy of $150 \mathrm{~mJ}$ and a repetition rate of $1 \mathrm{~Hz}$. The LIBS system used in this study consisted of six fibre-optics connected to compact optical spectrometers (Avantes, AvaSpec, Netherlands), which covered the spectral range of 185-904 $\mathrm{nm}$. Moreover, a sample chamber, X-Y-Z translation stage (XYZ-750, Applied Photonics Limited) and a miniature CCD camera enabling the observation of the positioning of the samples as well as the size and shape of the craters generated by laser ablation were also incorporated to the LIBS system. A schematic experimental setup used to collect LIBS spectra is shown in Fig. 1.

The best quality spectra were obtained at a constant optimum focal length of $76 \mathrm{~mm}$. Samples were measured directly in air. To achieve adequate sampling, each spectrum was taken at 100 locations for the same sample/pellet in a $10 \times 10$ grid pattern and moved by a step size of $0.70 \mathrm{~mm}$. To obtain the best signal-to-noise ratio, each spectrum was the result of 2 accumulations per location. Lifetime of the plasma is generally shorter than $1 \mathrm{~ms}$, thus to avoid the detection of strong bremsstrahlung, the continuum plasma emission was measured at the minimum integration time of $1.1 \mathrm{~ms}$ and the minimum gate delay of $1.27 \mu \mathrm{s}$. Different gate delay times were tested and the increase of this parameter resulted in deteriorated signal to noise ratio.

\subsection{Chemometric analysis}

The chemometric analysis was carried out using $\mathrm{R}$ ( $\mathrm{R}$ Core Team, 2016). Data analyses were performed using principal component analysis (PCA) and PLSR methods. Firstly 100 laser shots were averaged to obtain a single spectrum per analysed pellet. Data were pre-treated using combinations of pre-processing techniques to remove non-linearities and variation signals introduced by matrix effects and fluctuations in the laser pulse energy. Before applying PCA and PLSR modelling to the averaged spectra, data were baseline corrected. PCA using leave-one-out cross-validation was employed to detect outlying samples and visually explore sample distribution and clustering. Outlying spectra were determined using the Hotelling $\mathrm{T}^{2}$ ellipse with $99 \%$ confidence limit.

The package "pls" was used for conducting multivariate analysis with PLSR (Mevik, Wehrens, \& Liland, 2016). PLSR models were developed on spectral data (X-values) and chemical reference data (Y-values) for the prediction of magnesium content in infant formula mixtures. The data was divided into a training set (batch 1c and batch $2 \mathrm{c} ; \mathrm{n}=30$ ) and a validation set (batch $3 \mathrm{v} ; \mathrm{n}=21$ ) used to ensure the model robustness. For cross-validation, the leave-oneout method was selected. The model performance was evaluated by the coefficients of determination and the values of root mean square error for calibration $\left(\mathrm{R}^{2}\right.$, RMSEC) and cross-validation $\left(\mathrm{R}_{\mathrm{cV}}^{2}\right.$, a

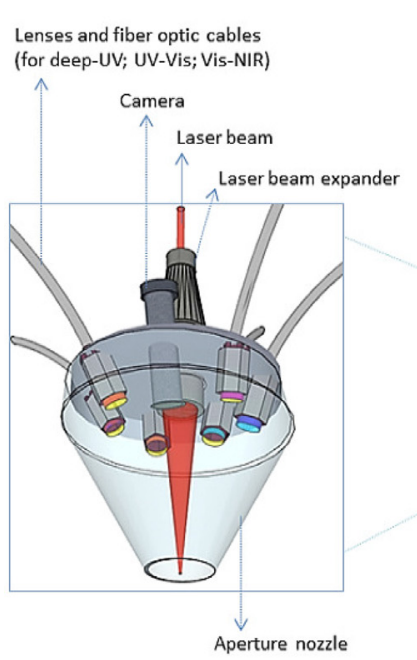

b

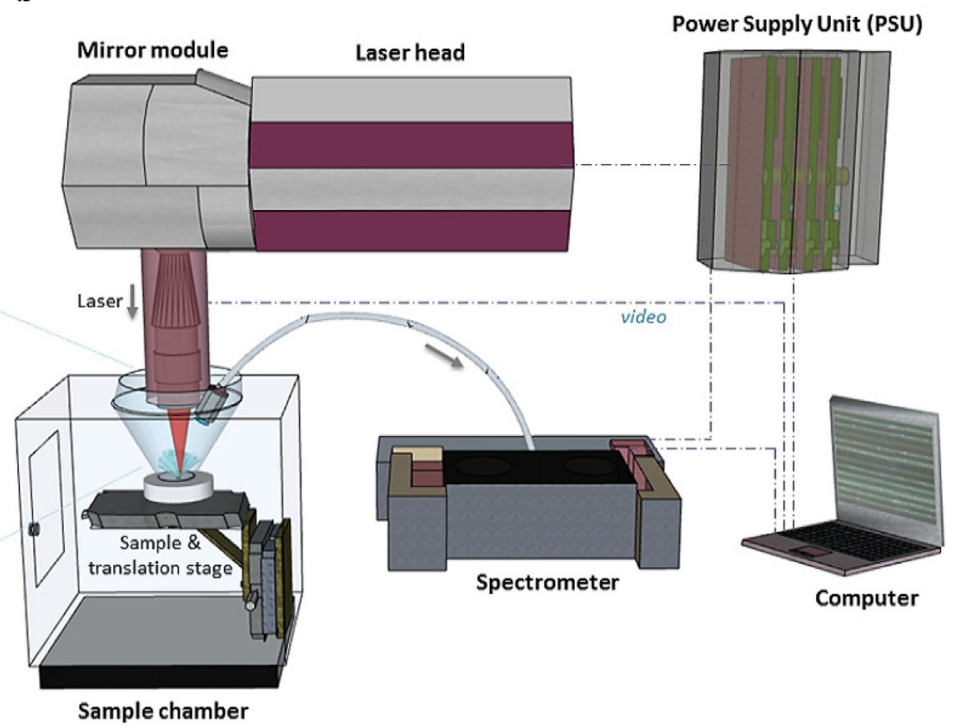

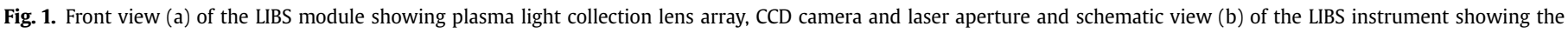
major components: laser head, mirror module, sample chamber, spectrometer, power supply unit and computer. 
RMSECV) as well as for prediction ( $\mathrm{R}^{2}$, RMSEP) when the validation data set was used.

Additionally, the limit of detection (LOD) was calculated according to the pseudounivariate approach (LODpu) for PLS models proposed by Allegrini and Olivieri (2014). This procedure was performed using equation (1):

$\operatorname{LOD}_{\mathrm{pu}}=\frac{3.3}{s_{p u}}\left[\left(1+h_{0 \min }+\frac{1}{I}\right) \operatorname{Var}_{p u}\right]^{1 / 2}$

where $S_{p u}$ is the slope of the pseudounivariate line, $h_{0} \min$ is the minimum leverage when the analyte concentration is zero, $I$ is the number of samples employed for calibration, and $v a r_{p u}$ is the variance of the regression residuals.

\section{Results and discussion}

\subsection{AAS analysis}

AAS was performed as a reference method for magnesium determination. All calibration and validation samples $(n=51)$ were tested with AAS. The results, expressed as $\mathrm{mg} \mathrm{kg}^{-1}$ in dry matter, are shown in Table 2. The analysis results of AAS for pure IF ranged from 400 to $430 \mathrm{mg} \mathrm{kg}^{-1}$ and were generally higher than the values declared by the producer ( $340 \mathrm{mg} \mathrm{kg}^{-1}$ ); however, they were still within the range for first infant formula powder provided by the Codex Alimentarius.

\subsection{Spectral analysis}

Typical LIBS spectra of IF powder is presented in Fig. 2. Before the spectra inspection, spectra of 51 experimental mixtures were baseline corrected to remove undesired systematic variation such as baseline shifts, scattering effects and effects from uncontrolled external factors such as to particle size and powder compression.

The recorded LIBS spectra covered the wavelength range from 180 to $900 \mathrm{~nm}$, in the UV, visible and infrared light regions. Fig. 3 illustrates the spectra of batch $3 \mathrm{v}$ that are an average of 3 samples ( 3 replicates each; 9 spectra for each mixture) and shows the strong atomic and ionic lines of magnesium in the spectral regions 280, 285 and $518 \mathrm{~nm}$. Magnesium ionic emission lines were detected at 279.55 and $280.27 \mathrm{~nm}$, while emission lines from neutral $\mathrm{Mg}$ were detected at 285.21, 517.26 and $518.36 \mathrm{~nm}$. The highest intensity was found at $279.55 \mathrm{~nm}$; however, saturation at this emission line occurred for samples with a high concentration of magnesium. As a result, the electrons accumulated on the saturated pixels started filing the closest pixel which is located just below. In literature, this phenomenon is referred as blooming and can be observed in Fig. 3 (Rai \& Thakur, 2007).

Table 2

Magnesium content in dry matter of the calibration and validation samples determined by AAS.

\begin{tabular}{llll}
\hline Sample name & \multicolumn{2}{l}{ Mg content $\left(\mathrm{mg} \mathrm{kg}^{-1}\right.$ dry matter $)$} \\
\cline { 2 - 4 } & Batch 1 & Batch 2 & Batch 3 \\
\hline Mg 1 & $175 \pm 4$ & $187 \pm 23$ & $163 \pm 9$ \\
Mg 2 & $298 \pm 9$ & $307 \pm 2$ & $319 \pm 18$ \\
Mg V1 & - & - & $353 \pm 6$ \\
IF & $423 \pm 1$ & $434 \pm 2$ & $434 \pm 4$ \\
Mg 3 & $559 \pm 26$ & $511 \pm 11$ & $506 \pm 16$ \\
Mg V2 & - & - & $612 \pm 17$ \\
Mg 4 & $919 \pm 40$ & $776 \pm 10$ & $810 \pm 19$ \\
\hline
\end{tabular}

a Values are the mean \pm standard deviation of three replicates.
As observed in Fig. 3 a clear increase in the intensity of $\mathrm{Mg}$ emission lines for samples with increasing $\mathrm{Mg}$ content can be observed. Other elements identified from the spectra included minerals such as calcium, potassium, sodium and organic elements such as $\mathrm{H}, \mathrm{N}, \mathrm{C}$ and $\mathrm{O}$. The emission bands from diatomic species such as $\mathrm{CN}$ or $\mathrm{C}_{2}$ also appeared in the recorded spectra indicating the organic nature of the samples, however, they were fewer than for metals. All emission lines have been identified according to the NIST database (NIST, 2018).

\subsection{Principal component analysis (PCA)}

A PCA score plot using all the samples' spectra at the selected wavelengths of 279.55, 280.28, 285.21, 517.26 and $518.36 \mathrm{~nm}$ is shown in Fig. 4. PC1 and PC2 accounted for 95\% and 3\% of the variance, respectively. There was no outlying sample observed and all the samples were located inside the ellipse of the Hotelling $\mathrm{T}^{2}$ with 99\% confidence limit. Samples were found to locate in the distribution pattern of different $\mathrm{Mg}$ content levels and along the up-down to the left-right direction in the 2-D plot.

\subsection{Partial least squares regression modelling for quantitative analysis}

Quantitative analysis of $\mathrm{Mg}$ content in the examined samples based on LIBS spectra was performed by applying PLSR modelling. When applied to the spectra, the aim of the PLSR analysis was to find a mathematical relationship between reference values and regions of LIBS spectra where strong intensities of the wavelengths assigned to $\mathrm{Mg}$ can be observed.

\subsection{Model calibration and validation}

For the quantification purpose, a calibration model was constructed based on the pre-processed, baseline corrected spectral data from batches $1 \mathrm{c}$ and $2 \mathrm{c}$. The model was developed using wavelength ranges from 273.46 to $297.02 \mathrm{~nm}$ and from 449.06 to $520.45 \mathrm{~nm}$ where all strong magnesium emission lines were observed. The residual errors for the predicted and the actual concentration of $\mathrm{Mg}$ in the samples were calculated in both calibration and cross-validation conditions.

To build a robust, neither over- nor under-fitted model, it is critical to determine the optimal number of latent variables (LVs). Generally, selecting too many LVs may lead to the situation when the model is unstable as it is overfitting the data. When an overfitted model occurs, it describes random noise instead of the underlying relationship between observations and predictors. In turn, choosing too few LVs implies an under-fitted model that incorporates insufficient information of the data (Deng et al., 2015). According to Deng et al. (2015) methods often used to choose the optimum LVs of a PLSR model include the Mallows' Cp statistic, Akeike information criterion, Bayesian information criterion and cross-validation (CV). In this study, CV using the leave-one-out method was applied to estimate the quality of the calibration equations and number of LVs. To do so, one spectrum was left out from the dataset, and the remaining data were used to build the model, which was then applied to the remaining 'validation' spectrum (Morsy \& Sun, 2013). The remaining spectrum was then reintroduced, in the place of another spectrum and the calibration and prediction process was repeated until every sample had been used for both calibration and validation. The root mean square error of CV (RMSECV) was used to select the optimal LVs, which was 3. The first and second LVs explained $93.04 \%$ and $3.99 \%$ of the variance respectively, while the third accounted for $0.67 \%$ of the variance. 


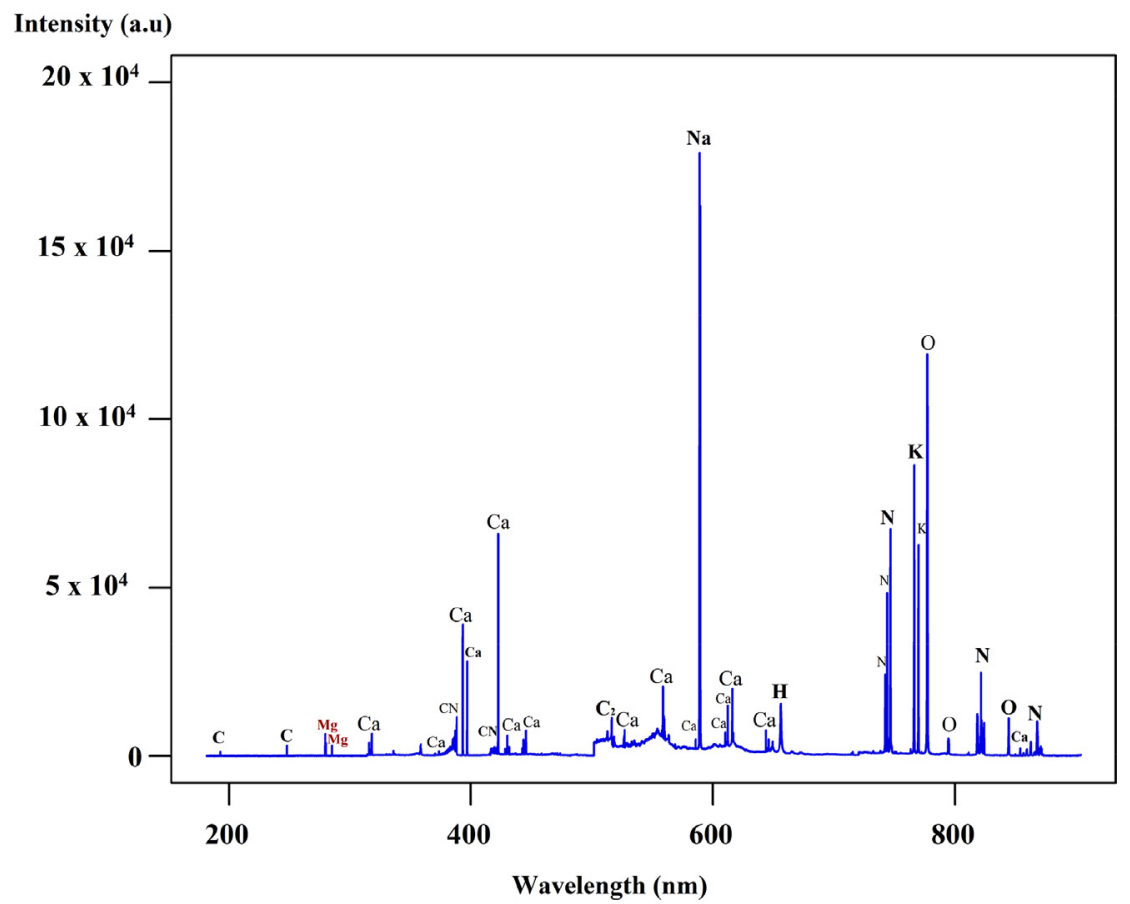

Fig. 2. Baseline-corrected LIBS spectra of infant formula powder.
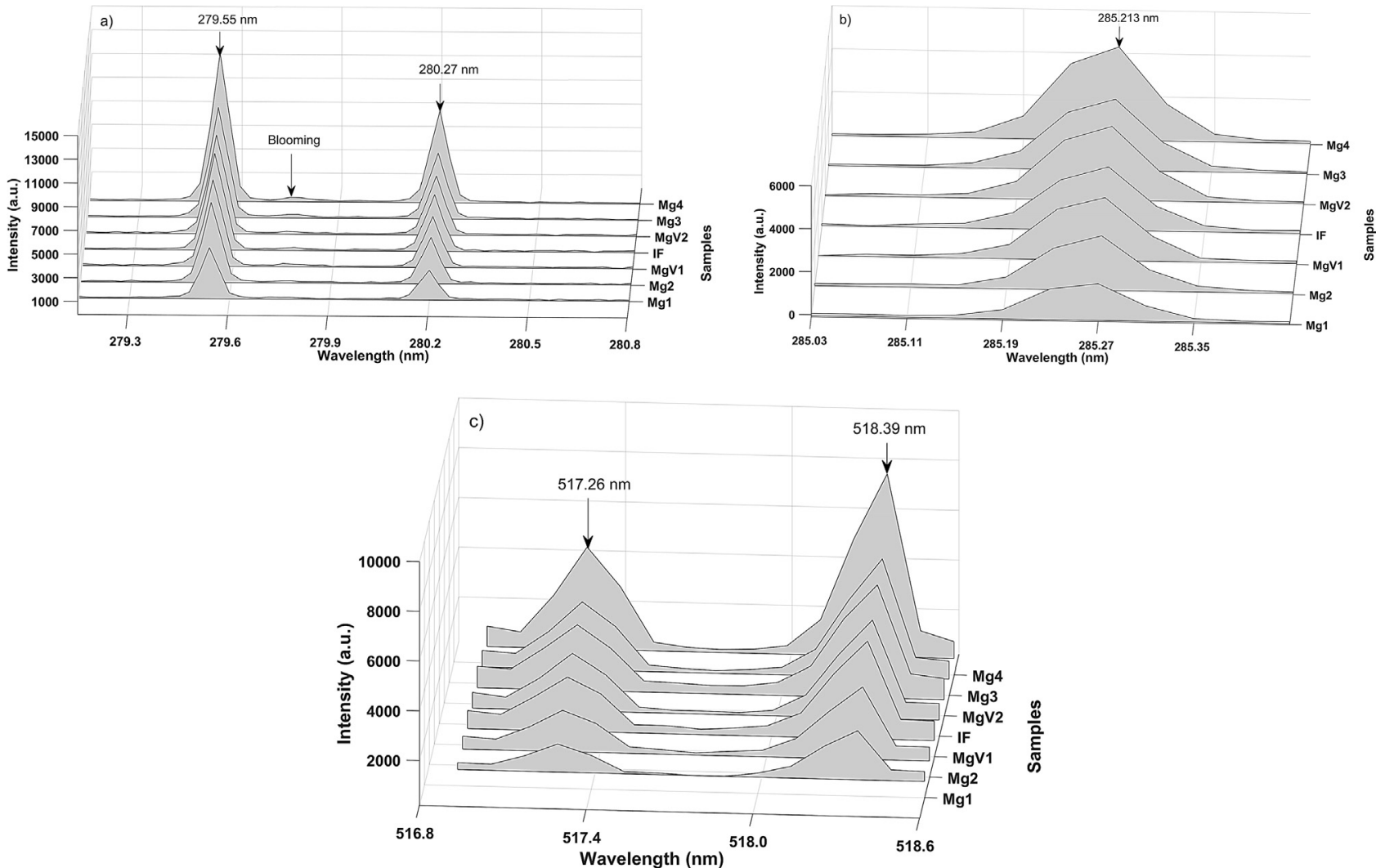

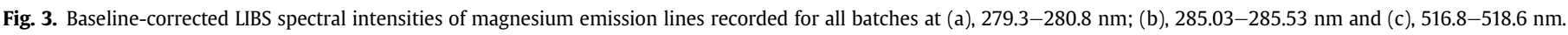

The values of $\mathrm{R}^{2} \mathrm{cv}$ were slightly lower than $\mathrm{R}^{2}$ and RMSECV higher than RMSEC which indicate that the model was not over-fitted.

Validation was carried out by applying the calibration model to predict the magnesium content in the samples from the validation set, i.e., batch 3v. Fig. 5b shows the scatter plots of the actual and predicted contents of $\mathrm{Mg}$ in the validation batch. It can be seen on the validation plot that the prediction established for the highest level of magnesium was slightly less accurate than for the 


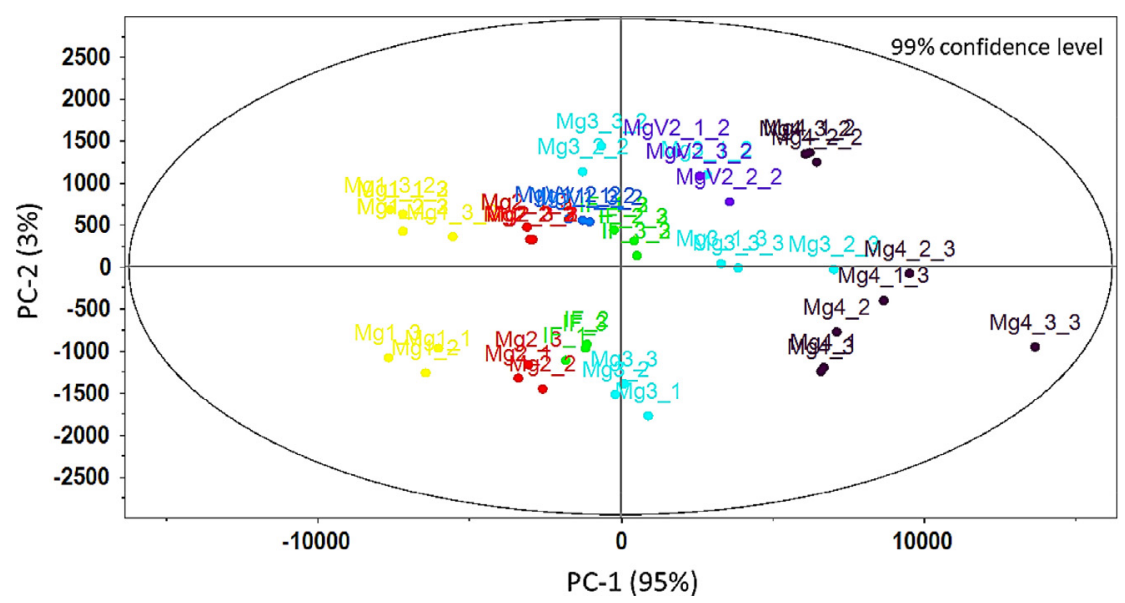

Fig. 4. PCA score plot of PC1 vs PC2 with the ellipse of the Hotelling $\mathrm{T}^{2}$ at $99 \%$ confidence level.
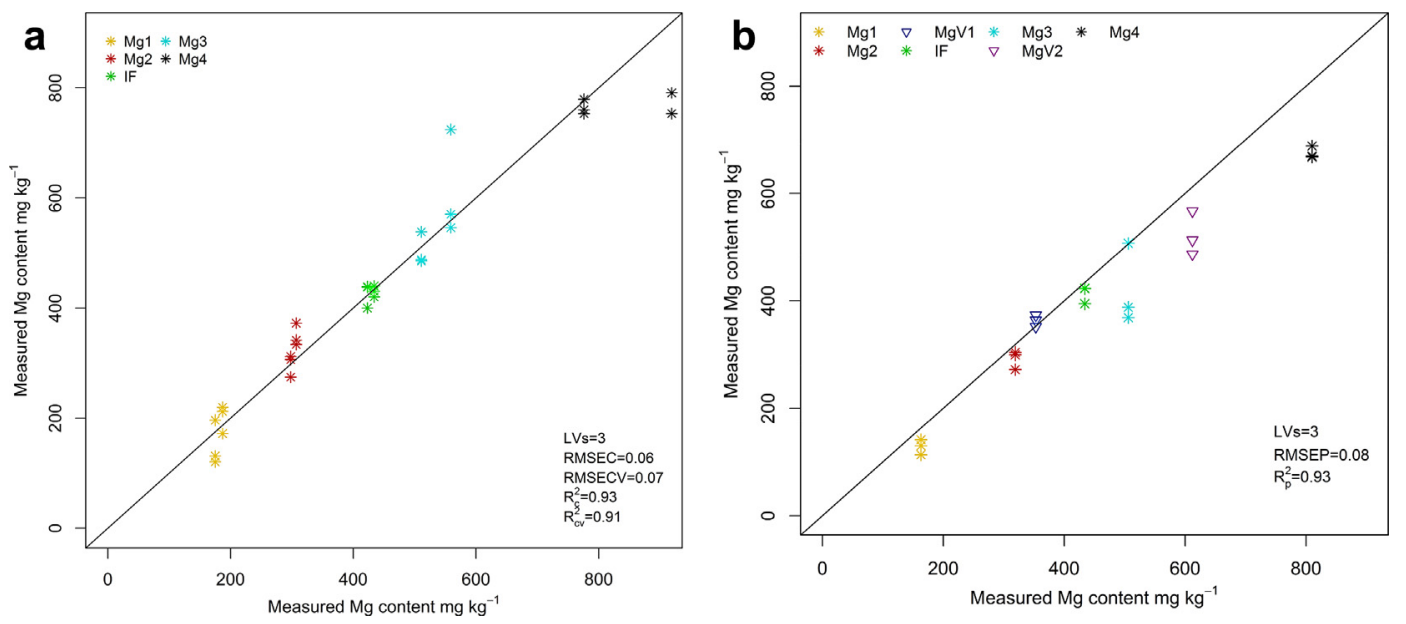

Fig. 5. PLS calibration for cross-validation (a) and validation (b) models of magnesium content in infant formula mixtures.

remaining levels. This might be due to the saturation, which occurred at emission line $279.55 \mathrm{~nm}$ for samples with high $\mathrm{Mg}$ content. Nevertheless, the RMSEP value was similar to the value of RMSECV, indicating that the model was robust. The value of RMSEP corresponds to the mean error estimated in analogue to the RMSECV but using the validation samples (Braga et al., 2010). Table 3 presents the results for some figures of merit describing the performance of the calibration model obtained for the magnesium prediction. The low values of RMSEP and LOD confirm the validity of the LIBS technique for the quantification of $\mathrm{Mg}$ in IF. Considering these results, it can be indicated that the prediction models shown in Fig. 5b had a good performance in predicting $\mathrm{Mg}$ in an independent validation batch.

\subsection{Spatial mineral distribution}

The calibration model obtained was further tested to predict the spatial mineral distribution of $\mathrm{Mg}$ content $\left(\mathrm{mg} \mathrm{kg}^{-1} \mathrm{DM}\right)$ in each pellet of the validation batch 3v. Fig. 6 shows the spatial mineral distribution of $\mathrm{Mg}$ content for all samples in batch $3 \mathrm{v}$. A clear distinction of the samples based on their Mg content can be seen, indicated by colour changes from blue for low $\mathrm{Mg}$ concentrations (e.g., Mg1) to red for high Mg concentrations (e.g., Mg4). Fig. 6 also shows similar colour pattern between replicates in general, meaning their $\mathrm{Mg}$ content was similar, with the exception of replicate 1 of $\mathrm{Mg} 3$ that differed from the other replicates. This can also be observed in Fig. 5, where two of the replicates of Mg3 had similar predicted values to IF, as also seen in Fig. 6, and one of the replicates had a higher content than IF. In general, from the mineral distribution observation, samples were relatively homogeneous with $\mathrm{Mg}$ content evenly distributed, which confirms the robustness of the calibration and validation model.

The results presented show the suitability of LIBS to provide spatial information and therefore potential to be used on heterogeneous samples as well as showing the potential of LIBS as a future quality monitoring tool.

Table 3

Performance of PLSR calibration model (Batch 1 and 2) and PLSR validation model (Batch 3) in predicting Mg contents in infant formula powders.

\begin{tabular}{|c|c|c|c|c|c|c|c|c|c|c|c|c|}
\hline \multirow[t]{2}{*}{ Element } & \multicolumn{8}{|c|}{ Calibration (Batch 1 and 2) } & \multicolumn{4}{|c|}{ Validation (Batch 3) } \\
\hline & $\begin{array}{l}\text { No. of } \\
\text { samples }\end{array}$ & $\begin{array}{l}\text { No. of } \\
\text { components }\end{array}$ & $\mathrm{R}_{\mathrm{C}}^{2}$ & $\begin{array}{l}\text { RMSEC } \\
\left(\mathrm{mg} \mathrm{kg}^{-1}\right)\end{array}$ & $\mathrm{R}_{\mathrm{CV}}^{2}$ & $\begin{array}{l}\text { RMSECV } \\
\left(\mathrm{mg} \mathrm{kg}^{-1}\right)\end{array}$ & Intercept & $\overline{\text { Slope }}$ & $\begin{array}{l}\text { No. of } \\
\text { samples }\end{array}$ & $\mathrm{R}_{\mathrm{p}}^{2}$ & $\begin{array}{l}\text { RMSEP } \\
\left(\mathrm{mg} \mathrm{kg}^{-1}\right)\end{array}$ & $\begin{array}{l}\text { LOD } \\
\left(\mathrm{mg} \mathrm{kg}^{-1}\right)\end{array}$ \\
\hline Magnesium & 30 & 3 & 0.97 & 40 & 0.94 & 57 & 0.002 & 0.995 & 21 & 0.85 & 77 & 150 \\
\hline
\end{tabular}


Replicate 1 Replicate 2 Replicate 3

$\operatorname{Mg} 1$
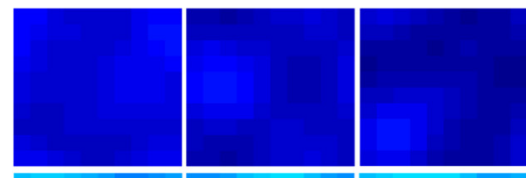

Mg 2
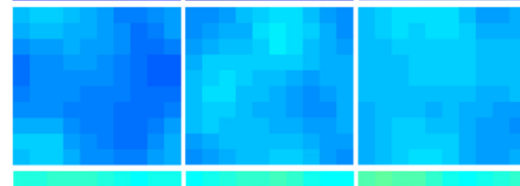

Mg V1
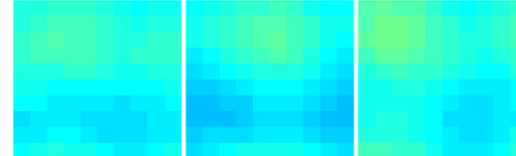

IF
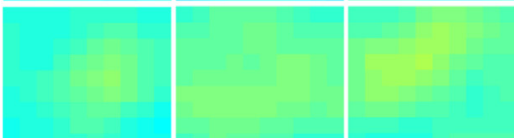

Mg 3
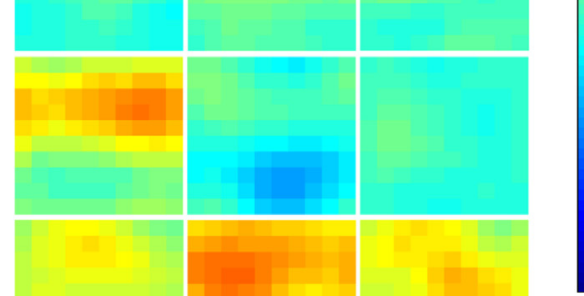

300

200

Mg V2

$\mathrm{Mg} 4$
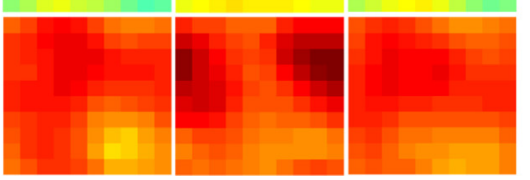

Fig. 6. Mineral spatial distribution of predicted Mg content of batch 3; the colour scale indicates the $\mathrm{Mg}$ content in $\mathrm{mg} \mathrm{kg}^{-1} \mathrm{DM}$. (For interpretation of the references to colour in this figure legend, the reader is referred to the Web version of this article).

\section{Conclusions}

In conclusion, PLSR was successfully used to reduce spectral multidimensionality data and to identify the most relevant wavelengths to $\mathrm{Mg}$ content. The relatively high values of $\mathrm{R}_{\mathrm{p}}^{2}$ and low values of RMSEP demonstrated the good performance in prediction and confirm that LIBS is a reliable and sensitive method for the determination of $\mathrm{Mg}$ in IF and has good prediction ability, thus it can serve as a fast method for magnesium determination in IF. In addition, LIBS was able to distinguish spatially different $\mathrm{Mg}$ contents within a batch of different samples, indicating the suitability of LIBS to provide spatial information and therefore potential use on heterogeneous samples. Consequently, the LIBS technique can be considered as an interesting alternative to the wet chemistry reference methods.

The strict regulations on the permitted levels of minerals within IF powders require rapid tools of the analysis and monitoring of the inorganic composition of IF. Traditionally, minerals in IF are monitored by taking samples over multiple time points and analysing them off-line using, for example ICP-MS. LIBS as microdestructive, reagent-free technique, gives the possibility of more frequent and faster measurements. Consequently, it can contribute to better process understanding as well as to real-time process control. As such it has the potential to be employed as a PAT tool for routine analysis and for monitoring the minerals during production process. The presented results as well as results already published, confirm that LIBS coupled with chemometrics is offering high specificity and sensitivity and can be successfully employed for determination and quantification of major elements in IF (CamaMoncunill et al., 2017, 2018). It should be expected that the role of LIBS technique in food industry will expand as demand for environmental friendly, rapid methods with low total ownership costs is growing.

\section{Acknowledgements}

This work was supported by the Department of Agriculture, Food and the Marine, Ireland (Grant agreement: 14/F/866).

\section{References}

Alfarraj, B. A., Sanghapi, H. K., Bhatt, C. R., Yueh, F. Y., \& Singh, J. P. (2018). Qualitative analysis of dairy and powder milk using laser-induced breakdown spectroscopy (LIBS). Applied Spectroscopy, 72, 89-101.

Allegrini, F., \& Olivieri, A. C. (2014). IUPAC-consistent approach to the limit of detection in partial least-squares calibration. Analytical Chemistry, 86, $7858-7866$

Bilge, G., Sezer, B., Eseller, K. E., Berberoglu, H., Koksel, H., \& Boyaci, I. H. (2016). Determination of $\mathrm{Ca}$ addition to the wheat flour by using laser-induced breakdown spectroscopy (LIBS). European Food Research and Technology, 242, 1685-1692.

Braga, J. W. B., Trevizan, L. C., Nunes, L. C., Rufini, I. A., Santos, D., \& Krug, F. J. (2010). Comparison of univariate and multivariate calibration for the determination of micronutrients in pellets of plant materials by laser induced breakdown spectrometry. Spectrochimica Acta - Part B Atomic Spectroscopy, 65, 66-74.

Cama-Mocunill, X., Markiewicz-Keszycka, M., Cama-Moncunill, R., Dixit, Y., CasadoGavalda, M. P., Cullen, P. J., et al. (2018). Sampling effects on the quantification of sodium content in infant formula using laser-induced breakdown spectroscopy (LIBS). International Dairy Journal, 85, 49-55.

Cama-Moncunill, X., Markiewicz-Keszycka, M. Dixit, Y, Cama-Moncunill, R. Casado-Gavalda, M. P., Cullen, P. J., et al. (2017). Feasibility of laser-induced breakdown spectroscopy (LIBS) as an at-line validation tool for calcium determination in infant formula. Food Control, 78, 304-310.

Casado-Gavalda, M. P., Dixit, Y., Geulen, D., Cama-Moncunill, R., Cama-Moncunill, X., Markiewicz-Keszycka, M., et al. (2017). Quantification of copper content with laser induced breakdown spectroscopy as a potential indicator of offal adulteration in beef. Talanta, 169, 123-129.

Deng, B. C., Yun, Y. H., Liang, Y. Z., Cao, D. S., Xu, Q. S., Yi, L. Z., et al. (2015). A new strategy to prevent over-fitting in partial least squares models based on model population analysis. Analytica Chimica Acta, 880, 32-41.

Hanley, K. J., Cronin, K., O'Sullivan, C., Fenelon, M. A., O'Mahony, J. A., \& Byrne, E. P. (2011). Effect of composition on the mechanical response of agglomerates of infant formulae. Journal of Food Engineering, 107, 71-79.

Jahnen-Dechent, W., \& Ketteler, M. (2012). Magnesium basics. Clinical Kidney Journal, 5, i3-i14.

Kim, G., Kwak, J., Choi, J., \& Park, K. (2012). Detection of nutrient elements and contamination by pesticides in spinach and rice samples using laser-induced breakdown spectroscopy (LIBS). Journal of Agricultural and Food Chemistry, 60, $718-724$.

Lei, W. Q., El Haddad, J., Motto-Ros, V., Gilon-Delepine, N., Stankova, A., Ma, Q. L., et al. (2011). Comparative measurements of mineral elements in milk powders with laser-induced breakdown spectroscopy and inductively coupled plasma atomic emission spectroscopy. Analytical and Bioanalytical Chemistry, 400, 3303-3313.

Markiewicz-Keszycka, M., Cama-Moncunill, X., Casado-Gavalda, M. P., Dixit, Y., Cama-Moncunill, R., Cullen, P. J., et al. (2017). Laser-induced breakdown spectroscopy (LIBS) for food analysis: A review. Trends in Food Science \& Technology, 65, 80-93.

Markiewicz-Keszycka, M., Casado-Gavalda, M. P., Cama-Moncunill, X., CamaMoncunill, R., Dixit, Y., Cullen, P. J., et al. (2018). Laser-induced breakdown spectroscopy (LIBS) for rapid analysis of ash, potassium and magnesium in gluten free flours. Food Chemistry, 244, 324-330.

Mevik, B.-H., Wehrens, R., \& Liland, K. H. (2016). Partial least squares and principal component regression (R package version 2.6-0). Vienna, Austria: R Foundation.

Morsy, N.. \& Sun, D.-W. (2013). Robust linear and non-linear models of NIR spectroscopy for detection and quantification of adulterants in fresh and frozenthawed minced beef. Meat Science, 93, 292-302.

Multari, R. A., Cremers, D., Dupre, J. A. M., \& Gustafson, J. E. (2013). Detection of biological contaminants on foods and food surfaces using laser-induced breakdown spectroscopy (LIBS). Journal of Agricultural and Food Chemistry, 61, 8687-8694.

NIST. (2018). NIST atomic spectra database. Retrieved from: https://physics.nist.gov/ PhysRefData/ASD/lines_form.html.

R Core Team. (2016). R: A language and environment for statistical computing. Vienna, Austria: R Foundation. 
Rai, V. N., \& Thakur, S. N. (2007). Instrumentation for laser-induced breakdown spectroscopy. In J. P. Singh, \& S. N. Thakur (Eds.), Laser-induced breakdown spectroscopy (1st ed., pp. 113-134). Oxford, UK: Elsevier.

Rai, A. K., Yueh, F. Y., Singh, J. P., \& Rai, D. K. (2007). Laser-induced breakdown spectroscopy of solid and molten material. In J. P. Singh, \& S. N. Thakur (Eds.) Laser-induced breakdown spectroscopy (1st ed., pp. 255-286). Oxford, UK: Elsevier.

Rigo, J., Pieltain, C., Christmann, V., Bonsante, F., Moltu, S. J., Iacobelli, S., et al. (2017). Serum magnesium levels in preterm infants are higher than adult levels: A systematic literature review and meta-analysis. Nutrients, 9, 1-24.
Silvestre, D. M., Barbosa, F. M., Aguiar, B. T., Leme, F. O., \& Nomura, C. S. (2015). Feasibility study of calibration strategy for direct quantitative measurement of $\mathrm{K}$ and $\mathrm{Mg}$ in plant material by laser-induced breakdown spectrometry. Analytical Chemistry Research, 5, 28-33.

Thakur, S. N., \& Singh, J. P. (2007). Fundamentals of laser induced breakdown spectroscopy. In J. P. Singh, \& S. N. Thakur (Eds.), Laser-induced breakdown spectroscopy (1st ed., pp. 3-22). Oxford, UK: Elsevier.

Wang, X., Esquerre, C., Downey, G., Henihan, L., O'Callaghan, D., \& O'Donnell, C. (2018). Assessment of infant formula quality and composition using Vis-NIR, MIR and Raman process analytical technologies. Talanta, 183, 320-328. 